\title{
Haemato-Immunological and Histological Responses in Nile Tilapia, Oreochromis niloticus Exposed to Titanium Dioxide Nanoparticles
}

\author{
S.A.D.S. PERERA and ASOKA PATHIRATNE* \\ Department of Zoology, University of Kelaniya, Kelaniya 11600, Sri \\ Lanka \\ *Correspondence (asoka@kln.ac.lk)
}

\begin{abstract}
Increased industrial application of nanotechnology has potential to increase nanoparticle contaminations in aquatic ecosystems. However a large knowledge gap exists on influence of nanoparticles on fish populations inhabiting receiving waters. The present study reports the effects of exposure to aquatic suspensions of titanium dioxide nanoparticles $\left(\mathrm{TiO}_{2} \mathrm{NPs}\right.$, anatase, particle size $<25 \mathrm{~nm}: 0,1$, $10 \mathrm{mg} \mathrm{l}^{-1}$, for 7 and 14 days) on some haematological/ innate immune responses and histological structure of gills, liver and intestine of Nile tilapia, an economically important freshwater fish in tropical regions. The results show that $\mathrm{TiO}_{2} \mathrm{NPs}$ exposure conditions were not lethal to Nile tilapia but lead to blood parameter alterations and histopathological changes in the organs. Upon exposure of fish to both concentrations of $\mathrm{TiO}_{2} \mathrm{NPs}$ for 14 days, erythrocyte counts, haemoglobin levels, total leucocyte counts and percent neutrophils in the peripheral blood were increased significantly $(\mathrm{P}<0.05)$ in comparison to the control fish. Despite increases in neutrophils, total phagocytic and myeloperoxidase activities of the blood of fish exposed to $10 \mathrm{mg} \mathrm{L}^{-1} \mathrm{TiO}_{2} \mathrm{NPs}$ were depressed significantly $(\mathrm{P}<0.05)$ whereas respiratory burst activity was not altered. Serum lysozyme activities in the fish exposed to $10 \mathrm{mg} \mathrm{l}^{-1} \mathrm{TiO}_{2} \mathrm{NPs}_{\mathrm{N}}$ were elevated significantly $(\mathrm{P}<0.05)$ compared to the controls. Histological changes seen in the tilapia exposed to $\mathrm{TiO}_{2} \mathrm{NPs}$ were epithelial separation, mucous cell proliferation, hyperplasia and lamellae fusion in the gills; hepatocytes with vacuolations, pycnotic nuclei, apoptosis and necrosis in the liver; eroded villi epithelium, reduction of mucous cells and degeneration of mucosa of the intestine. Although blood parameter alterations seen in Nile tilapia can be considered as physiological responses of the fish to cope up with the $\mathrm{TiO}_{2} \mathrm{NPs}$ induced stress, observed organ pathologies could lead to serious health implications. Hence, detail studies with a range of environmentally relevant levels are warranted to investigate chronic effects of $\mathrm{TiO}_{2}$ nanoparticles on health of fish populations in the receiving water bodies. We recommend use of Nile tilapia as a tropical fish model for further studies on nanotoxicity.
\end{abstract}


Key words: Nile tilapia; $\mathrm{TiO}_{2}$; nanotoxicity; haematology; histology

\section{Introduction}

The properties of engineered nanoparticles that make them useful in a wide range of industrial applications have led to concerns on their potential impact on human and environmental health (Scown et al. 2010). Titanium dioxide nanoparticles $\left(\mathrm{TiO}_{2} \mathrm{NPs}\right)$ are one of the abundantly produced and mostly used engineered nanoparticles in industrial applications. As new types of photocatalysts, anti-ultraviolet light agents, and photoelectric effect agents, $\mathrm{TiO}_{2} \mathrm{NPs}$ are used in a variety of consumer products, paints and surface coatings, and in the environmental decontamination of air, soil and water (Kahru and Dubourguier 2010; Menard et al. 2011).

Nano- $\mathrm{TiO}_{2}$ is photoinducible, redox active and thus a generator of potential reactive oxygen species (ROS) at its surfaces in the presence of UV light (Armelao et al. 2007) or in the absence of UV light (Reeves et al. 2008). The toxicity of nanoparticles is generally governed by properties such as particle size, shape, and surface properties (Kahru and Dubourguier 2010). Of the different crystalline forms of $\mathrm{TiO}_{2} \mathrm{NPs}$, anatase phase which exhibits the highest photocatalytic activity is considered as toxic to biological systems (Gurr et al. 2005). The aquatic environment is particularly at risk of exposure to these nanoparticles, as it acts as a sink for most environmental contaminants.

As an ultrafine-sized material, the $\mathrm{TiO}_{2} \mathrm{NPs}$ may enter the fish body through respiratory tract, gastrointestinal tract and skin. Information on toxicity of $\mathrm{TiO}_{2} \mathrm{NPS}$ are available for a few fishes such as common carp, Cyprinus carpio (Hao et al. 2009), fathead minnow, Pimephales promelas (Hall et al. 2009; Jovanovic' et al. 2011); rainbow trout Oncorhynchus mykiss (Federici et al. 2007; Boyle et al. 2013) and zebra fish, Danio rerio (Griffitt et al. 2008; Wang et al. 2011; Ramsden et al. 2013). Based on the available acute toxicity data, Kahru and Dubourguier, (2010) classified $\mathrm{TiO}_{2}$ NPs as 'harmful' (L(E)C $\mathrm{C}_{50}: 10-100 \mathrm{mg} \mathrm{l}^{-}$ ${ }^{1}$ ). Sub-lethal effects found in these fish species following the $\mathrm{TiO}_{2} \mathrm{NPs}$ exposure include oxidative stress, depression of ATP-ase activity, induction of organ pathology, depression of growth rate (Menard et al. 2011) and impairment of reproduction (Wang et al. 2011; Ramsden et al. 2013). However, further studies with ecologically relevant test species are necessary for the generation of ecotoxicological data for hazard assessment of the nanoparticles (Handy et al. 2012). In a recent review, Jovanović and Palić (2012) pointed out that most nanoparticle types present in the aquatic environment, such as $\mathrm{TiO}_{2}$, do not exhibit or have very low direct toxicity, but instead display silent or concealed sub-lethal effects on the fish immune system with serious implications. However, there is a gap in current available information regarding the immunotoxic potential of engineered nanoparticles toward aquatic organisms (Jovanović and Palić 2012).

Haemato-immunological and histological assessments provide important information on the general physiology and health status of fish populations under investigation. Nile tilapia, Oreochromis niloticus, is a wide spread teleost fish in 
tropical regions where it has a significant economic value in fishery and aquaculture industries. Due to hardy nature, this fish is also used as a bioindicator organism to assess pollution impacts under tropical conditions (Pathiratne et al. 2009). However, little information is available on effects of engineered nanoparticles on the health of tropical fish populations. Therefore, the present study was carried out to assess the potential toxicity associated with the exposure to aqueous suspensions of $\mathrm{TiO}_{2} \mathrm{NPs}$ (Anatase nanopowder) on Nile tilapia using survival, haematological \& innate immune responses and histological structure of the gills, liver and intestine as end points.

\section{Materials and Methods}

\section{Titanium dioxide nanoparticles}

Powder form of $\mathrm{TiO}_{2}$ NPs (Anatase, CAS number: 1317-70-0) was purchased from Sigma-Aldrich Company, MO, USA. According to the manufacturer, the particle size is $<25 \mathrm{~nm}$ and specific surface area is $45-55 \mathrm{~m}^{2} \mathrm{~g}^{-1}$. The composition is $99.7 \%$ trace metal basis and the bulk density is $0.04-0.06 \mathrm{~g} \mathrm{ml}^{-1}$.

\section{Test fish}

Nile tilapia fingerlings were obtained from Udawalawe Aquaculture Development Centre of National Aquaculture Development Authority of Sri Lanka. The fish were acclimated to laboratory conditions in fiberglass aquaria with aged tap water under continuous aeration for three months. During the acclimation period, fish were fed daily with commercial fish food pellets (Prima, Grain Elevators Limited, Sri Lanka). Nile tilapia used in the experimental exposure studies (15-25 cm in total length) were free of gross lesions or parasitic infections externally and considered as apparently healthy individuals.

\section{Exposure of fish to Titanium dioxide nanoparticles}

Glass aquaria with only aged tap water and two concentrations $\left(1 \mathrm{mg} \mathrm{l}^{-1}\right.$ and 10 $\mathrm{mg} \mathrm{l}^{-1}$ ) of $\mathrm{TiO}_{2}$ NPs in aged tap water with duplicates were used as exposure media. Required amounts of $\mathrm{TiO}_{2}$ NPs were suspended in $10 \mathrm{ml}$ of deionized water and the suspension was vortexed vigorously for $5 \mathrm{~min}$ and added into the glass aquaria containing $60 \mathrm{~L}$ of aged tap water. The aquaria water with $\mathrm{TiO}_{2}$ NPs suspension was mixed thoroughly with a glass rod for 5 minutes and six fish were introduced in to each aquarium and exposure studies were conducted for 14 days. The fish introduced in to the aquaria with aged tap water were considered as controls. The aquaria water was subjected to vigorous aeration continuously using air pumps in order to minimize aggregation of nanoparticles. Control aquaria were also subjected to vigorous aeration. Swimming pattern and opercular movement rates of the control fish and the fish exposed to $\mathrm{TiO}_{2} \mathrm{NPs}$ were recorded after one hour and two hours of the exposure. Fish were not fed initially for 4 days and fed once on every two days at $1 \%$ of the body weight before renewing the exposure media with $\mathrm{TiO}_{2}$ NPs in every two days. At 7 days of exposure, three fish were randomly taken from each aquarium and were subjected to haemato-immunological and histopathological studies. 
The fish were anesthetized using benzocaine and their body weights were recorded. Blood samples were collected from the fish by bleeding the caudal vein. The gills ( $2^{\text {nd }}$ gill arch on left side), portions of the main lobe of the liver, and the anterior part of the intestine were dissected and preserved in neutral buffered formalin for histology. Weight of spleen was also measured in each fish for determination of the spleen-somatic index (percentage of spleen weight to body weight). Remaining fish in each aquarium were processed as described above at 14 days after the initial exposure. General water quality parameters of the exposure media during the study period were as follows: water temperature $27-29^{\circ} \mathrm{C}, \mathrm{pH}$ 7-8 and dissolved oxygen concentration 4.5-5.5 $\mathrm{mg} \mathrm{l}^{-1}$.

\section{Haematological and immunological parameters}

Blood samples were taken into heparinized microcapillary tubes and haematocrit values were determined by the haematocrit gauge after centrifuging the tubes in a haematocrit centrifuge. Total erythrocyte count and leucocyte count were determined using Shaw's solutions as dilution fluids following the method of Hesser (1960). Haemoglobin content was determined following the absorbance at $540 \mathrm{~nm}$ using the Cyanohaemoglobin method with the Drabkins' Reagent (Sigma-Aldrich, MO, USA). Total haemoglobin concentration was determined using the haemoglobin standard curve. For differential leucocyte counts, blood smears were prepared from each fish and fixed in $100 \%$ methanol and stained with Wright-Giemsa stain. Different types of leucocytes were identified as described by Hibiya (1982). A total of 100 leucocytes were observed from each stained smear and the relative abundance of different leucocytes was determined.

Phagocytic activity of neutrophils and monocytes were determined by the method described by Anderson and Siwicki (1995). A sample (0.1 mL) of blood was placed in a microtiter plate well and $0.1 \mathrm{ml}$ of formalin killed Staphylococcus aureus $1 \times 10^{7}$ cells suspended in phosphate buffered saline $(\mathrm{pH}$ 7.2) was added and mixed well with a pipette to ensure contact of bacteria with leucocytes. Then bacteria-blood solution was incubated for $20 \mathrm{~min}$ at room temperature. Five $\mu \mathrm{L}$ of the bacteria-blood solution was taken into a glass slide and a smear was made. The slide was fixed with $95 \%$ ethyl alcohol for 5 min and air-dried. Then the slides were stained with Giemsa stain for $10 \mathrm{~min}$. Two smears were made from each fish. The total of 100 neutrophils and monocytes were counted under light microscope and numbers of observed phagocytizing cells were counted. Total phagocytic activity was determined as a percentage of active phagocytizing cells in comparison to the total neutrophils and monocytes counted.

Myeloperoxidase activity was determined using the procedure described by Anderson and Siwicki (1995). Blood smears were fixed with formaldehydeethanol fixative for 30 seconds and washed gently with running tap water for 2 min and allowed to air dry in the dark for $10 \mathrm{~min}$. Two smears were made from each fish. The slides were placed in peroxide indicator reagent solution (SigmaAldrich, MO, USA) containing $\mathrm{H}_{2} \mathrm{O}_{2}$ in Trizmal buffer for $30 \mathrm{~min}$ in the dark. The slides were washed with running tap water for 15 seconds allowed to air dry and counterstained with acid haematoxyline solution for 10 minutes. The slides 
were washed and allowed to dry and myeloperoxidase active cells were counted under the bright field microscope. Myeloperoxidase activity is presented as percent of positive cells in comparison to the total neutrophils and monocytes counted.

Respiratory burst activity in the blood by production of oxygen radicals was measured using nitroblue tetrazolium (NBT) dye as described by Anderson and Siwicki (1995). A sample of heparinized blood $(0.1 \mathrm{ml})$ was placed into a microtiter plate well and $0.1 \mathrm{ml}$ of $0.2 \%$ NBT solution was added, the NBTblood cell suspension was incubated for $30 \mathrm{~min}$ at room temperature. An aliquot (0.05 mL) of the NBT-blood cell suspension was added into a glass tube containing $1.0 \mathrm{~mL} \mathrm{~N}, \mathrm{~N}$-dimethylformamide. The mixture was centrifuged for 5 $\min$ at $3000 \mathrm{~g}$. Then the absorbance of the supernatant was measured at $540 \mathrm{~nm}$ using a spectrophotometer. Respiratory burst activity is expressed as absorbance units at $540 \mathrm{~nm}$.

Lysozyme activity of blood serum was determined as described by Anderson and Siwicki (1995). Blood serum was prepared by centrifuging the non heparinized blood at $3000 \mathrm{~g}$ for $5 \mathrm{~min}$. A sample $(0.1 \mathrm{~mL})$ of serum was placed into a test tube and it was diluted with (1:1) phosphate buffered saline. Then 0.5 $\mathrm{mL}$ suspension of Micrococcus lysodeikticus (Sigma-Aldrich, MO, USA) whose concentration has been determined by spectrophotometric method to given $40 \%$ transmission was added and mixed well. The absorbance was measured by spectrophotometric method at $540 \mathrm{~nm}$ at 1, 2, 3 and $30 \mathrm{~min}$ and the rate of change of absorbance was calculated. Absorbance value of $0.001 \mathrm{~min}^{-1}$ was considered as 1 lysozyme unit min $^{-1}$.

\section{Histology}

The preserved specimens of gill, liver and intestine were subjected to standard dehydration procedure and were embedded in paraffin wax. Histological sections were obtained with the thickness of $5 \mu \mathrm{m}$ using a rotary microtome and stained with haematoxylin and eosine. Abnormalities of the tissues (Hibiya 1982) were examined under light microscope to assess the structural alterations, if any, caused by $\mathrm{TiO}_{2}$ NPs exposure.

\section{Data analysis}

Data were compared using one-way analysis of variance (ANOVA) to examine the differences in treatment effects in comparison to relevant control fish groups (Zar 1999). If differences were significant, they were compared using Tukey's pair wise comparison test. The accepted level of significance was $\mathrm{P}<0.05$.

\section{Results}

Upon exposure to the aqueous suspensions of $\mathrm{TiO}_{2} \mathrm{NPs}$, opercular movement rates of Nile tilapia were significantly increased in comparison to the control fish during the observation period (Fig. 1). Erratic swimming patterns especially jerky uncoordinated movements were observed in the fish exposed to $10 \mathrm{mg} \mathrm{l}^{-1} \mathrm{TiO}_{2}$ 
NPs. However activities were reduced and the fish became lethargic by the $14^{\text {th }}$ day of the $\mathrm{TiO}_{2}$ NPs exposure.

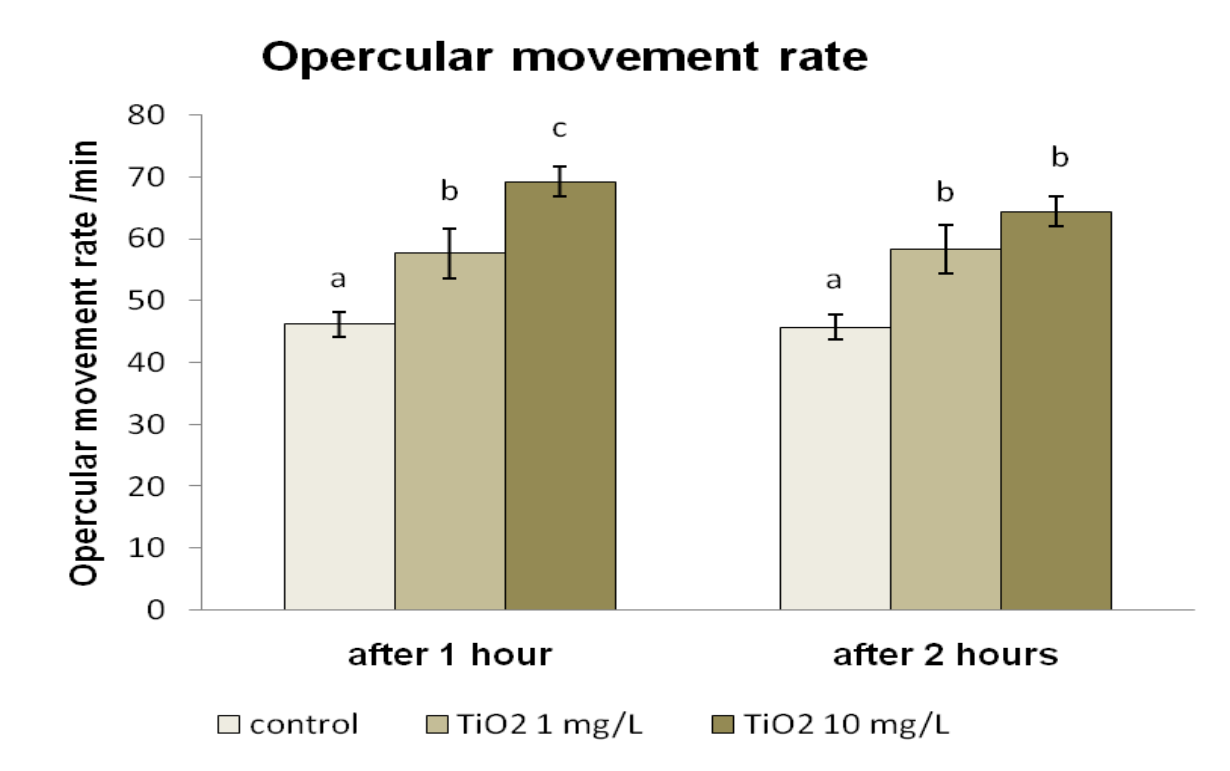

Figure 1. Opercular movement rates of Nile tilapia exposed to $\mathrm{TiO}_{2}$ nanoparticles. Data are presented as mean \pm SEM $(n=12)$. For each exposure period, bars with different letters are significantly different from each other (ANOVA, Tukey's test, $\mathrm{P}<0.05$ )

No mortalities of the Nile tilapia were observed during the exposure period of 14 days. Although vigorous aeration provided effective means of mixing to maintain homogeneity of the suspensions, aggregation of NPs occurred at both concentrations of $\mathrm{TiO}_{2}$ NPs. It was observed that the fish ingested water containing aggregates of $\mathrm{TiO}_{2}$ NPs during exposure period. In the dissected fish, whitish aggregates, presumably agglomerates of ingested $\mathrm{TiO}_{2} \mathrm{NPs}$, were observed within the intestine lumen of the fish exposed to $\mathrm{TiO}_{2} \mathrm{NPs}$. The gill surface of the fish exposed to $10 \mathrm{mg} \mathrm{l}^{-1} \mathrm{TiO}_{2}$ NPs was covered with mucus secretions.

Haemato-immunological parameters (Table 1) indicate significantly higher erythrocyte counts (1.7 folds) and haemoglobin levels (1.6 folds) in the peripheral blood of Nile tilapia exposed to both concentrations of $\mathrm{TiO}_{2} \mathrm{NPs}$ for 14 days in comparison to the control fish. No significant differences were observed in relation to the haematocrit levels. Total leucocyte counts were significantly higher in the fish exposed to both concentrations of $\mathrm{TiO}_{2} \mathrm{NPs}$ (1.81.9 folds) irrespective of the exposure duration (Table 1). Differential leucocyte counts indicate percentage of neutrophils was significantly higher (1.2 folds) in 
the fish exposed to $10 \mathrm{mg} \mathrm{l}^{-1} \mathrm{TiO}_{2}$ NPs. However total phagocytic active cells and myeloperoxidase active cells were significantly decreased in the fish exposed to $10 \mathrm{mg} \mathrm{l}^{-1} \mathrm{TiO}_{2}$ NPs (Table 1) where as the respiratory burst activity (NBT activity) was not altered significantly. Serum lysozyme activity was increased significantly in the fish exposed to $10 \mathrm{mg} \mathrm{l}^{-1} \mathrm{TiO}_{2}$ NPs. Spleen-somatic index of the fish was not altered significantly by the $\mathrm{TiO}_{2} \mathrm{NP}$ exposure (Table 1).

Normal histological structure was observed in the gills, liver and intestine sections of the control Nile tilapia (Fig. 2-4). The exposure to both concentrations of $\mathrm{TiO}_{2}$ NPs resulted in epithelial separation, thickening of the primary gill lamella and secondary gill lamellae due to epithelial hyperplasia and fusion of secondary gill lamella (Fig. 2). Numerous swollen mucus cells were also seen in the gills of all the fish exposed to $10 \mathrm{mg} \mathrm{l}^{-1} \mathrm{TiO}_{2} \mathrm{NPs}$. Liver tissues of the fish exposed to both concentrations of $\mathrm{TiO}_{2}$ NPs displayed hepatocytes with vacuolations, condensed/pycnotic nuclei and apoptosis (Fig. 3). Necrosis of the liver tissue was prominently seen in all the fish exposed to $10 \mathrm{mg} \mathrm{l}^{-1} \mathrm{TiO}_{2}$ NPs for 14 days. The intestines of the fish exposed to $\mathrm{TiO}_{2} \mathrm{NPs}$ showed microscale particles (presumably ingested aggregates of $\mathrm{TiO}_{2} \mathrm{NPs}$ ). Erosion of villi epithelium and degenerated intestinal mucosa were observed in all Nile tilapia exposed to both concentrations of $\mathrm{TiO}_{2}$ NPs (Fig. 4). Mucus cells were rare in the gut mucosa of the fish exposed to $\mathrm{TiO}_{2} \mathrm{NPs}$ for 14 days. Histological alterations were more conspicuous in the fish exposed to $10 \mathrm{mg} \mathrm{l}^{-1} \mathrm{TiO}_{2} \mathrm{NPs}$ concentrations for 14 days in comparison to the fish exposed to the other exposure levels.

\section{Discussion}

Available acute toxicity data of $\mathrm{TiO}_{2}$ NPs on the tested fish species indicate low acute toxicity of $\mathrm{TiO}_{2} \mathrm{NPs}$ within the exposure period studied: the 48-h $\mathrm{LC}_{50}$ for Pimephales promelas $>500 \mathrm{mg} \mathrm{l}^{-1}$, the $96-\mathrm{h} \mathrm{LC}_{50}$ for Oncorhynchus mykiss $>100$ $\mathrm{mg} \mathrm{L}^{-1}$ and no lethal effects on Danio rerio were observed below $500 \mathrm{mg} \mathrm{l}^{-1}$ (Menard et al. 2011). The present study showed that 14 day exposure of $1 \mathrm{mg} \mathrm{l}^{-1}$ or $10 \mathrm{mg} \mathrm{l}^{-1}$ concentrations of $\mathrm{TiO}_{2}$ NPs were not lethal to Oreochromis niloticus (Nile tilapia) but lead to alterations in haemato-immunological parameters and histological changes in the gill, liver and intestinal tissues of the fish. Observed higher opercular movement rates and erratic swimming patterns in the fish exposed to $10 \mathrm{mg} \mathrm{l}^{-1} \mathrm{TiO}_{2} \mathrm{NPs}$ during the initial exposure periods could probably be due to the turbid conditions associated with the nanoparticle suspensions. This study is the first report of the evaluation of toxic effects of nanoparticles on the commercially important tropical fish, Nile tilapia. 
Table 1. Haemato-immunological parameters in the peripheral blood and spleensomatic index of Nile tilapia following water borne exposure to $\mathrm{TiO}_{2}$ nanoparticles.*

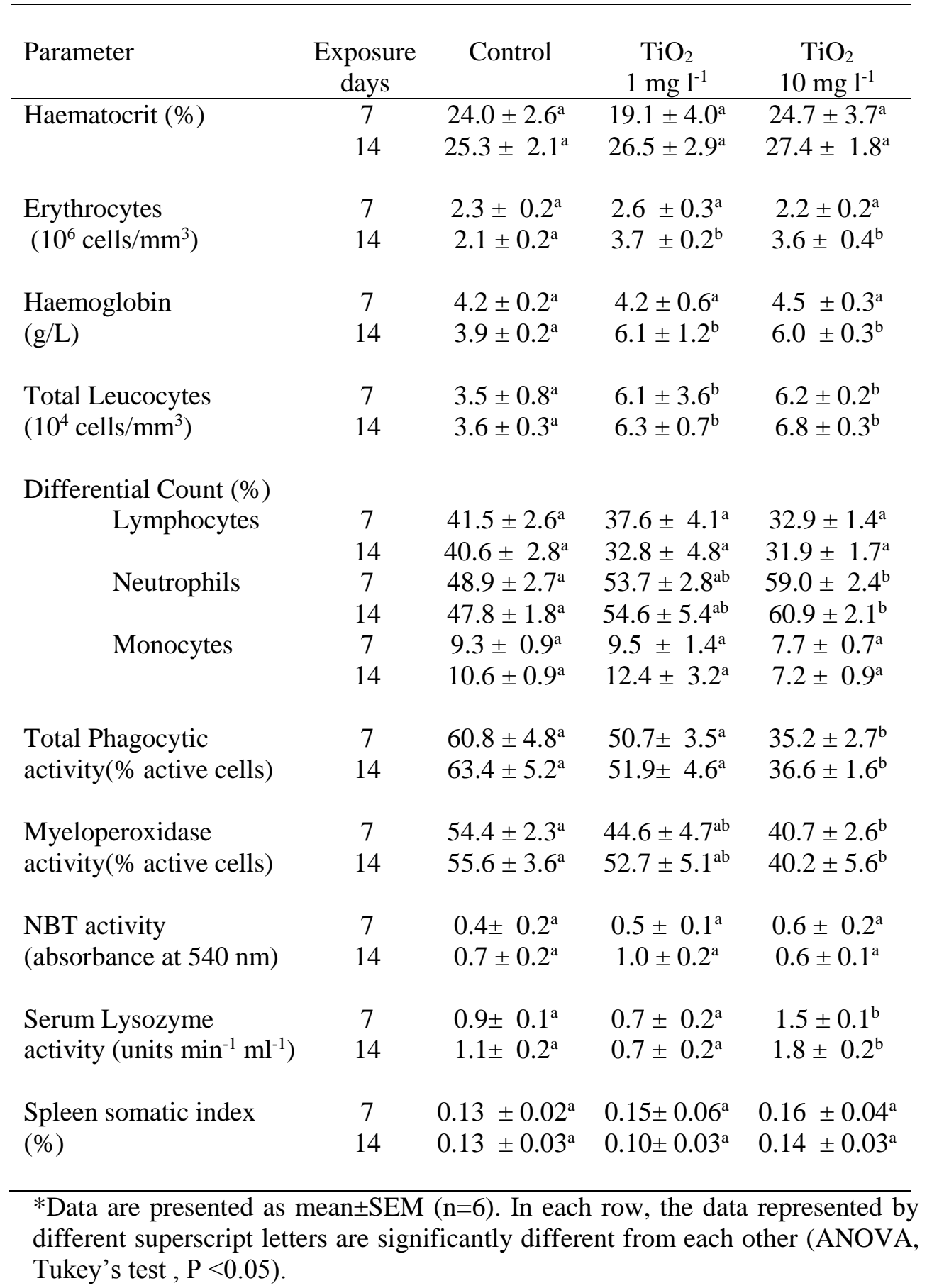




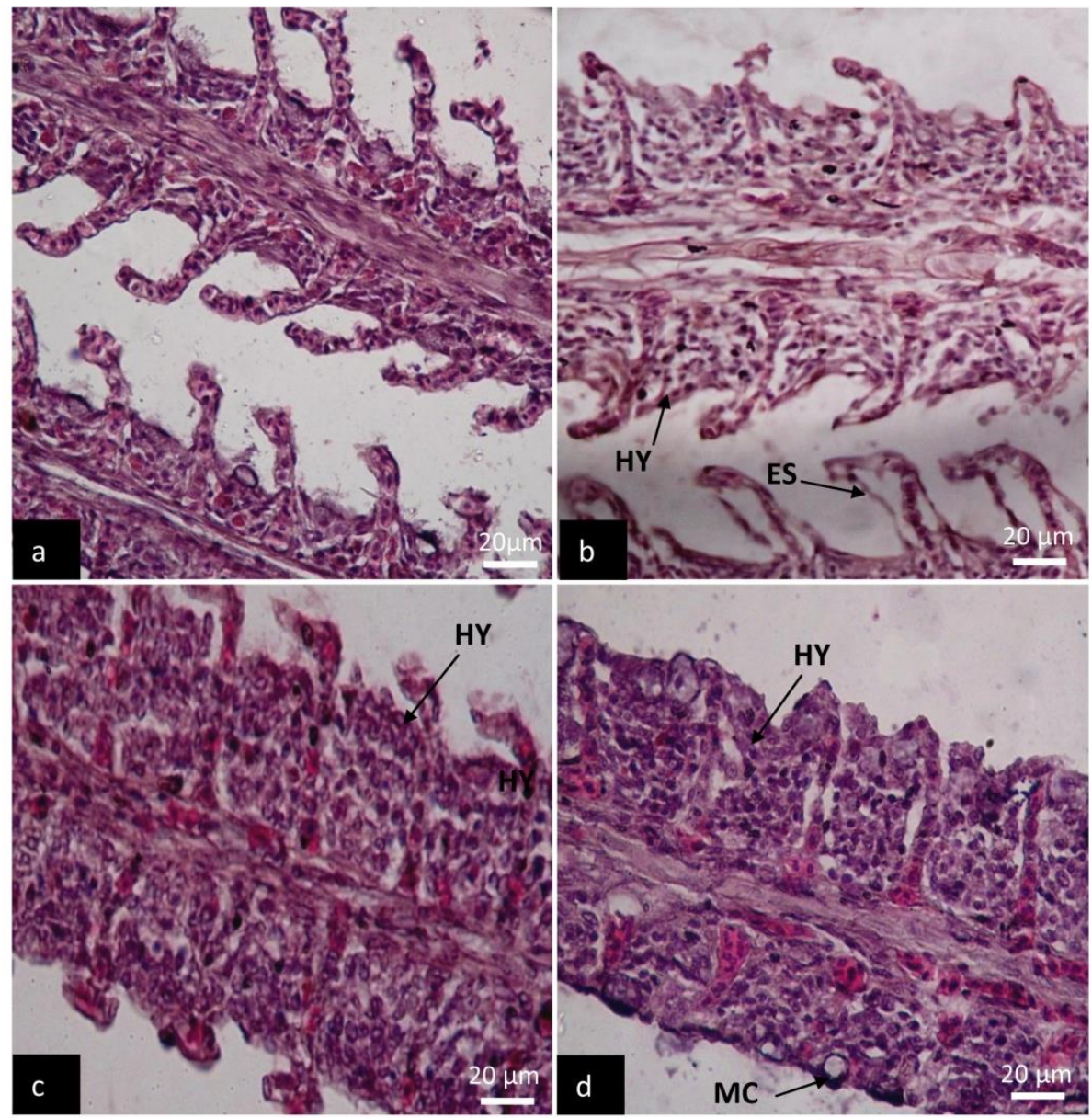

Figure 2. Histological structure of gill lamellae of control Nile tilapia (a) showing normal histology and the Nile tilapia exposed to water borne $\mathrm{TiO}_{2}$

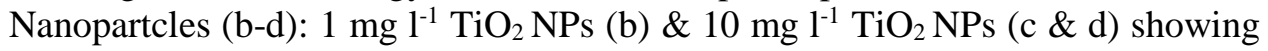
epithelial seperation (ES), hyperplasia lamella fusion (HY) and mucus cell proliferation (MC) 

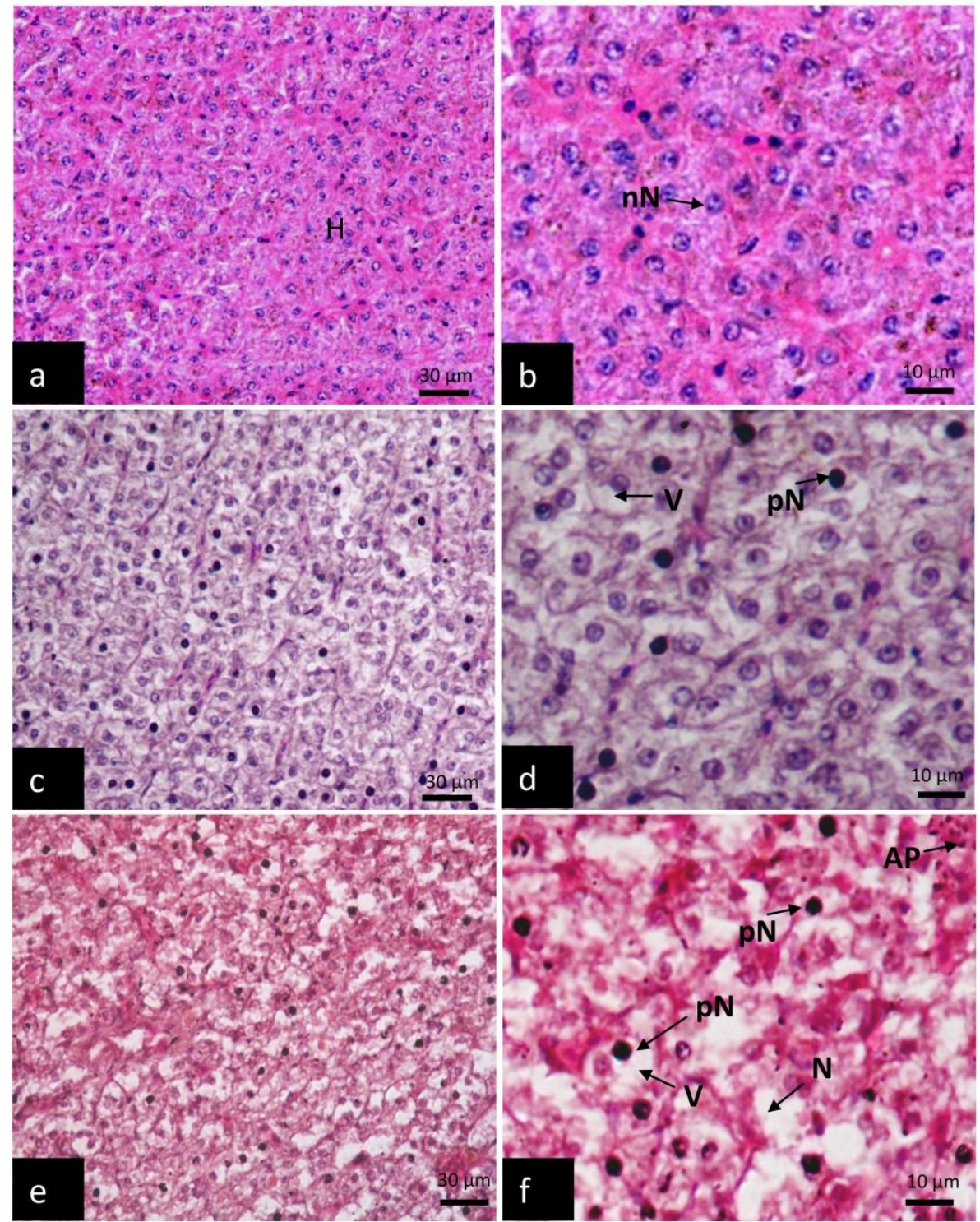

Figure 3. Histological structure of liver of control Nile tilapia (a \& b) showing normal histology- hepatocytes $(\mathrm{H})$ with normal nuclei $(\mathrm{nN})$ and the Nile tilapia exposed to water borne $\mathrm{TiO}_{2}$ nanoparticles: $1 \mathrm{mg} \mathrm{l}^{-1} \mathrm{TiO}_{2} \mathrm{NPs}(\mathrm{c} \& \mathrm{~d}), 10 \mathrm{mg} \mathrm{l}^{-1}$ $\mathrm{TiO}_{2}$ NPs (e \& f) showing hepatocytes with pycnotic nuclei (pN), apoptosis(AP), vacuolation $(\mathrm{V})$ and necrosis $(\mathrm{N})$. 

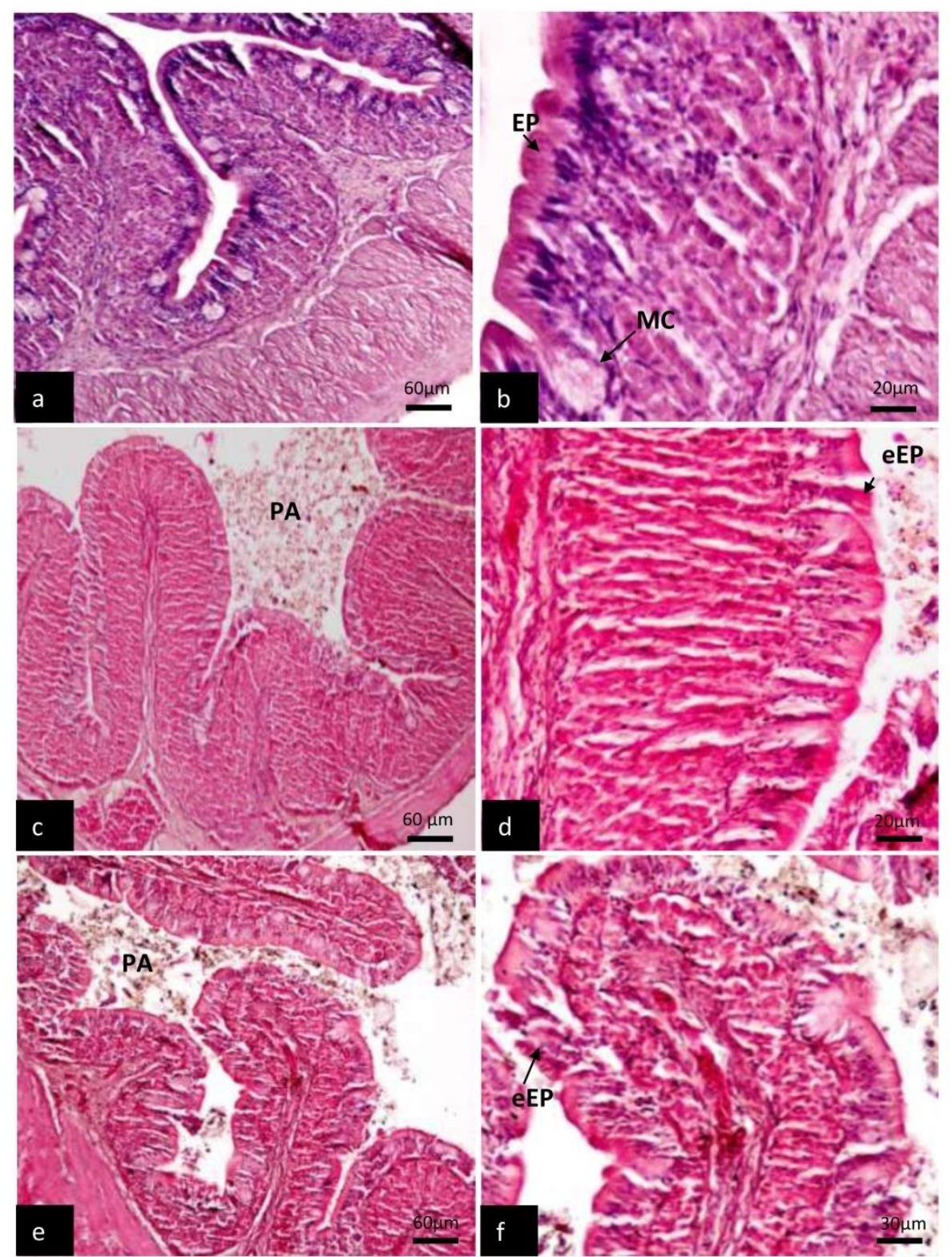

Figure 4. Histological structure of intestine of control Nile tilapia (a \& b) showing normal histology (EP-villi epithelium; M-mucus cell) and the Nile tilapia exposed to water borne $\mathrm{TiO}_{2}$ nanoparticles: $1 \mathrm{mg} \mathrm{l}^{-1} \mathrm{TiO}_{2} \mathrm{NPs}$ (c \& d), 10 $\mathrm{mg}^{-1} \mathrm{TiO}_{2}$ NPs (e \& f) showing aggregates of particles in the lumen (PA), diminished mucus cells and epithelial erosion (eEP) and degenerated mucosa 
Enumeration of haematological parameters in the peripheral blood is routinely used to assess general physiological responses in fish subjected to a variety of environmental stressors. A few studies have been carried out earlier to investigate effects of $\mathrm{TiO}_{2} \mathrm{NP}$ on erythrocytic parameters of fishes. In rainbow trout, 14 day exposure to $0.1-1.0 \mathrm{mg} \mathrm{l}^{-1}$ of $\mathrm{TiO}_{2}$ NPs (crystal structure of $25 \%$ rutile; $75 \%$ anatase; particle size $21 \mathrm{~nm}$ with surface area of $50 \pm 15 \mathrm{~m}^{2} \mathrm{~g}^{-1}$ ) did not cause alterations in erythrocyte counts, haematocrit and haemoglobin levels in the blood (Federici et al. 2007). Rainbow trout fed with 10 or $100 \mathrm{mg} \mathrm{kg}^{-1} \mathrm{TiO}_{2}$ NPs (structure, particle size and surface area same as above) in the diets for 8 weeks had no major disturbances in erythrocyte or leucocyte counts, haematocrits and haemoglobin levels in the blood (Ramsden et al. 2009). Erythrocyte counts from whole blood samples of zebra fish exposed to $0.1 \mathrm{mg} \mathrm{l}^{-1}$ and $1 \mathrm{mg} \mathrm{l}^{-1} \mathrm{TiO}_{2}$ NPs (structure, particle size and surface area same as above) at days 7 and 14 showed no obvious effects compared to the control (Ramsden et al. 2013) whereas rainbow trout exposed to $1 \mathrm{mg} \mathrm{l}^{-1} \mathrm{TiO}_{2}$ NPs (structure, particle size and surface area same as above) for 14 days resulted in increases in haematocrit and haemoglobin levels in the blood, 22 fold increases in the Ti concentrations of gill tissue and gill pathologies (Boyle et al. 2013). The increase in haematocrit and haemoglobin levels in the blood of rainbow trout exposed to $1 \mathrm{mg} \mathrm{l}^{-1} \mathrm{TiO}_{2} \mathrm{NPs}$ has been attributed as a compensation for respiratory hypoxia associated with the gill injuries (Boyle et al. 2013). In the present study, we have used $\mathrm{TiO}_{2} \mathrm{NPs}$ from a different source (Anatase powder, particle size $<25 \mathrm{~nm}$, surface area 45 $55 \mathrm{~m}^{2} \mathrm{~g}^{-1}$ ) and found significant increases in the erythrocyte counts and haemoglobin levels in the peripheral blood and structural changes in the gill tissue of Nile tilapia following exposure to $1 \mathrm{mg} \mathrm{l}^{-1}$ and $10 \mathrm{mg} \mathrm{l}^{-1}$ for 14 days. Observed increases in erythrocyte counts and haemoglobin levels in the blood of $\mathrm{TiO}_{2}$ NPs exposed Nile tilapia may be attributed to increase release of erythrocytes to the peripheral circulation from the erythropoietic organs, stimulated by high demand for oxygen and carbon dioxide transport due to impaired gaseous exchange across the structurally altered gill tissue (Fig. 2).

Innate immunity is the first line of defense against intrusion of foreign materials/agents in the fish body. Innate immunity is nonspecifically targeted by nanoparticles due to the phagocytic nature of their cells or their physical interaction with cell receptors or free proteins in plasma (Jovanovi'c, and Pali'c 2012). Of the different types of leucocytes in the fish blood, neutrophils and monocytes are phagocytic and capable of adhering to and engulfing invading particles and possess both extracellular and intracellular killing mechanisms (Evelyn 2002). Previous studies indicate that acute exposures of rainbow trout to $\mathrm{TiO}_{2}$ NPs (crystal structure of $25 \%$ rutile; $75 \%$ anatase; particle size $21 \mathrm{~nm}$ with surface area of $50 \pm 15 \mathrm{~m}^{2} \mathrm{~g}^{-1}$ ) did not cause observable changes in blood neutrophil counts (Federici et al. 2007; Ramsden et al. 2009). However more recent studies have reported significant effects of $\mathrm{TiO}_{2}$ NPs on leucocytic parameters of rainbow trout, zebra fish and fathead minnow. A decrease in leucocyte counts in the blood has been reported in rainbow trout exposed to $1 \mathrm{mg}$ $1^{-1} \mathrm{TiO}_{2}$ NPs for 14 days (Boyle et al. 2013) and in zebra fish following exposure to 0.1 and $1 \mathrm{mg} \mathrm{l}^{-1} \mathrm{TiO}_{2}$ NPs for 14 days (Ramsden et al. 2013). More 
recent study with fathead minnow injected intraperitoneally with $10 \mu \mathrm{g} \mathrm{g}^{-1} \mathrm{TiO}_{2}$ NPs (particle size $86 \mathrm{~nm}$, crystal structure and surface area not specified) per fish body weight indicate decrease in neutrophil function (oxidative burst, neutrophil extracellular trap release, degranulation of primary granules) of the fish after $48 \mathrm{~h}$ of exposure (Jovanovi'c et al 2011). In the present study, significant increase in leucocyte counts in the peripheral blood of the Nile tilapia was observed following 14 day exposure to 1 and $10 \mathrm{mg} \mathrm{l}^{-1} \mathrm{TiO}_{2} \mathrm{NPs}$ and percentage of neutrophils was significantly higher at $14 \mathrm{~d}$ exposure to $10 \mathrm{mg} \mathrm{l}^{-1} \mathrm{TiO}_{2} \mathrm{NPs}$. Despite increase in neutrophils, percent active total phagocytic cells and myeloperoxidase active cells in the blood of $10 \mathrm{mg} \mathrm{l}^{-1} \mathrm{TiO}_{2}$ NPs exposed Nile tilapia were decreased without significant alterations in the respiratory burst activity. Decreased phagocytic and myeloperoxidase activities in the fish despite of increase in neutrophils could be attributed to the inhibition of phagocytic function or the decreased number of recruitment of mature neutrophils to the peripheral circulation after longer term (14 d) exposure to $\mathrm{TiO}_{2} \mathrm{NPs}$. Toxicity of $\mathrm{TiO}_{2}$ NPs may involve generation of reactive oxygen species causing oxidative stress (Hao et al. 2009) and damage cell membranes causing disturbances in phagocytosis process. Neutrophils that are not fully mature have significantly lower levels of respiratory burst and other functions, and different developmental stages of neutrophils differ in granular content (Jovanovi'c, and Pali'c 2012). Observed reduction in neutrophil function despite of elevated neutrophil levels in the peripheral blood of Nile tilapia could be attributed to the release of immature neutrophils from fish haematopoetic organs to potentially supplement the depletion of mature neutrophil populations in the peripheral blood that interacted with the nanoparticles. Potential interactions between $\mathrm{TiO}_{2} \mathrm{NPs}$ and neutrophils could affect the neutrophils ability to control infections of pathogens in the natural environments and may cause decreased disease resistance in fish populations exposed to $\mathrm{TiO}_{2}$ NPs. It appears that the release of neutrophil extracellular traps (NETs) is a standard defensive attempt by neutrophils to remove nanoparticles from the system (Jovanovi'c, and Pali'c 2012). With the NET release stimulation by nanoparticles, a significant number of the mature neutrophil population inside the circulatory system of aquatic organism will die after exposure to $\mathrm{TiO}_{2} \mathrm{NPs}$ which may interfere with the defense responses as less mature neutrophils may not be fully functional, resulting in the reduction of neutrophil in vivo functional responses (Jovanovi'c, and Pali'c 2012).

Lysozyme is one of the main components associated with the nonspecific defense system in fish for killing extracellular bacteria. Lysozyme is abundant in fish mucus, blood plasma and lymphoid tissues. The main sources of the enzyme in the blood are phagocytic cells, neutrophils and monocytes, from which it is released into the blood plasma (Murray and Fletcher 1976). Lysozymes levels in blood are standard ecotoxicological biomarkers in fish and aquatic invertebrate studies (Whyte 2007). In the present study, serum lysozyme activities were significantly higher in Nile tilapia exposed to $10 \mathrm{mg} \mathrm{l}^{-1} \mathrm{TiO}_{2} \mathrm{NPs}$ for $14 \mathrm{~d}$ in comparison to the control fish. Observed increase in leucocytes coupled with neutrophils in the Nile tilapia exposed to $10 \mathrm{mg} \mathrm{l}^{-1} \mathrm{TiO}_{2} \mathrm{NPs}$ may have contributed to the increase in lysozyme activities in the serum. Elevated 
lysozyme levels in these fish reflect the attempts of the fish to cope with the stress induced by chronic $\mathrm{TiO}_{2}$ NPs exposure. In a study with an aquatic invertebrate model (marine blue mussel Mytilus galloprovincialis), metal-oxide nanoparticles (such as $\mathrm{TiO}_{2} \mathrm{NPs}$ and $\mathrm{SiO}_{2} \mathrm{NPs}$ ) and carbon-based nanoparticles (fullerenes) induced concentration-dependent increase in extracellular lysozyme activity and its release from haemocytes have been reported (Canesi et al. 2010). No previous reports on in vivo effects of $\mathrm{TiO}_{2} \mathrm{NPs}$ on serum lysozyme activities in fish are found in the literature. Hence, this study is the first report on $\mathrm{TiO}_{2} \mathrm{NPs}$ induced serum lysozyme activities in the fish.

In fish, the gills and intestine are main absorption sites of chemical toxicants. Liver is the main organ involved in xenobiotic metabolism. Histological alterations in these organs associated with sublethal exposure to $\mathrm{TiO}_{2} \mathrm{NPs}$ have been documented for a few species of fish. Exposure of common carp to 10- $200 \mathrm{mg} \mathrm{l}^{-1} \mathrm{TiO}_{2}$ NPs suspensions (rutile form, $50 \mathrm{~nm}$ particle size, surface area $30 \mathrm{~m}^{2} \mathrm{~g}^{-1}$ ) for 20 days resulted in the increase in the incidence of thickening, edema, fusion and hyperplasia in the gills (Hao et al. 2009). Edema and thickening of the gill lamellae have been reported in juvenile rainbow trout after waterborne exposure to $1 \mathrm{mg} \mathrm{l}^{-1} \mathrm{TiO}_{2} \mathrm{NPs}$ (25\% rutile/75\% anatase, $21 \mathrm{~nm}$ particle size, surface area $50 \mathrm{~m}^{2} \mathrm{~g}^{-1}$ ) for 14 days (Federici et al. 2007). In another study, rainbow trout exposed to $1 \mathrm{mg} \mathrm{l} \mathrm{l}^{-1}$ of the same $\mathrm{TiO}_{2} \mathrm{NPs}$ for 14 days induced gill injuries such as hyperplasia of the primary and secondary lamellae, oedema and club tips in the secondary lamellae, as well as swollen mucocytes in the gill epithelium (Boyle et al. 2013). However, exposure of zebra fish to 0.1 or $1.0 \mathrm{mg} \mathrm{L}^{-1}$ of the same type of $\mathrm{TiO}_{2} \mathrm{NPs}$ showed little evidence of treatment related morphological change in gill tissues (Ramsden et al. 2013). In the present study, sub lethal exposure to anatase form of $\mathrm{TiO}_{2} \mathrm{NPs}\left(1 \& 10 \mathrm{mg} \mathrm{l}^{-1}\right)$ for 14 days resulted in the epithelial separation in secondary lamella, hyperplasia, and lamellae fusion which could impair the proper functioning of gills of the fish. Proliferated mucus cells in the gills of fish exposed to $10 \mathrm{mg} \mathrm{l}^{-1} \mathrm{TiO}_{2} \mathrm{NPs}$ indicate that mucus defenses were active in these fish. Even though, increased mucus secretion by the gills is a common response of fish to aqueous pollutants, it did not fully protect the gills of Nile tilapia exposed to $\mathrm{TiO}_{2} \mathrm{NPs}$ as areas of structural damage were observed in the fish.

Nanoparticles may be taken up by the cells through macropinocytosis, phagocytosis or endocytosis (Jovanovi'c, and Pali'c 2012). Federici et al. (2007) reported that livers of juvenile rainbow trout had condensed nuclear bodies in liver cells after waterborne exposure to $1 \mathrm{mg} \mathrm{L}^{-1} \mathrm{TiO}_{2} \mathrm{NPs}$ (25\% rutile/75\% anatase, $21 \mathrm{~nm}$ particle size, surface area $50 \mathrm{~m}^{2} \mathrm{~g}^{-1}$ ) for 14 days. Liver structural alterations (necrotic and apoptosis hepatocytes) have also been observed in a study with common carp (Hao et al. 2009). In the present study, the liver tissue of Nile tilapia exposed to $\mathrm{TiO}_{2}$ NPs also showed structural alterations including hepatocytes with cytoplasmic vacuolations, condensed/pycnotic nuclear bodies and apoptosome including necrotic cell bodies and nuclear fragments which appeared to be apoptotic bodies. Necrotic condition in the liver tissues was severe in the Nile tilapia exposed to $10 \mathrm{mg} \mathrm{l}^{-1} \mathrm{TiO}_{2} \mathrm{NPs}$ for 14 days. Observed pathological changes indicate, liver tissue of Nile tilapia is sensitive to $\mathrm{TiO}_{2} \mathrm{NPs}$. 
Histological alterations in the liver tissues of fish exposed to aqueous suspensions of $\mathrm{TiO}_{2}$ NPs indicate that NPs have entered the liver tissue via the circulatory system.

$\mathrm{TiO}_{2}$ NPs may cause a stress-induced drinking response that could result in NP precipitation in the intestine lumen and induce pathology of the intestinal mucosa in fish (Federici et al. 2007). Water born exposure of rainbow trout to $0.1,0.5$, or $1.0 \mathrm{mg} \mathrm{l}^{-1} \mathrm{TiO}_{2}$ NPs for up to 14 days (Federici et al. 2007) induced intestinal pathologies especially with the higher concentration which included erosion of the villi, fusion and vacuolation of the intestinal mucosa. In the present study, we observed that intestine lumen of Nile tilapia exposed to $\mathrm{TiO}_{2}$ NPs was partially filled with white aggregates (presumably ingested agglomerates of $\mathrm{TiO}_{2}$ NPs) which may have induced mechanical aberrations in the intestinal mucosa. $\mathrm{TiO}_{2}$ NPs exposure induced pathology in the intestine of Nile tilapia was erosion of the villi epithelium, decline in mucous cells and degeneration of the intestinal mucosa. Inflammation of the gastric mucosa has also been noted in mice during dietary $\mathrm{TiO}_{2} \mathrm{NP}$ exposure (Wang et al. 2007). Our observation on $\mathrm{TiO}_{2} \mathrm{NPs}$ induced gill, liver and intestinal pathologies of Nile tilapia raised the concern about health of fish populations during chronic exposure to sub lethal levels of $\mathrm{TiO}_{2}$ NPs in the natural environment. A recent study demonstrated significant impairment of reproduction of zebra fish following chronic exposure to $0.1 \mathrm{mg} \mathrm{l}^{-1}$ $\mathrm{TiO}_{2}$ (Wang et al. 2011). Hence, more research efforts on chronic effects of environmentally relevant concentrations of $\mathrm{TiO}_{2} \mathrm{NPs}$ on health and reproduction of fishes are deserved for ecological risk assessment.

In conclusion, the present study revealed that the $\mathrm{TiO}_{2} \mathrm{NPs}$ exposure conditions (anatase, particle size <25nm: 0, 1, $10 \mathrm{mg} \mathrm{l}^{-1}$, for 7 and 14 days) were not lethal for Nile tilapia but lead to alterations in blood parameters and organ pathologies. Exposure of fish to both concentrations of $\mathrm{TiO}_{2} \mathrm{NPs}$ for 14 days induced significant increases in the erythrocyte counts, haemoglobin levels and total leucocyte counts and percent neutrophils in the peripheral blood. Serum lysozyme activities were significantly higher in the fish exposed to $10 \mathrm{mg} \mathrm{l}^{-1}$ $\mathrm{TiO}_{2}$ NPs in comparison to the control fish. Despite increases in neutrophils, percent active phagocytic cells and myeloperoxidase active cells were decreased in the fish exposed to $\mathrm{TiO}_{2}$ NPs nanoparticles suggesting that more immature neutrophils are released from fish hematopoietic organs to potentially supplement the depletion of mature neutrophil populations in the peripheral blood that interacted with the nanoparticles. Although haemato-immunological alterations seen in this study can be considered as physiological responses of Nile tilapia to cope up with the $\mathrm{TiO}_{2}$ NPs induced stress, observed organ pathologies in the fish could lead to serious health implications. Hence, more research efforts on longterm impact of environmentally relevant levels of engineered $\mathrm{TiO}_{2} \mathrm{NPs}_{\text {on fish }}$ health and reproduction are warranted. We recommend use of Nile tilapia, $O$. niloticus as a tropical fish model for further studies on nanotoxicity assessments as it is an economically important and environmentally relevant fish species in the tropical regions. 


\section{References}

Anderson, D.P. \& A.K. Siwicki 1995.

Basic haematology and serology for fish health programmes. In: Shariff M., J.R. Arthur \& R.P. Subasinghe (eds) Diseases in Asian Aquaculture II. Fish Health Section, Asian Fisheries Society, Manila, Philippines pp. 108-202.

Armelao, L, D. Barreca, G. Bottaro, A. Gasparotto, C. Maccato, \& C. Maragno 2007. Photocatalytic and antibacterial activity of $\mathrm{TiO}_{2}$ and $\mathrm{Au} / \mathrm{TiO}_{2}$ nanosystems. Nanotechnology 18: 7.

Boyle, D, G.A. Al-Bairuty, C.S. Ramsden, K.A. Sloman, T.B. Henry \& R. D. Handy 2013.

Subtle alterations in swimming speed distributions of rainbow trout exposed to titanium dioxide nanoparticles are associated with gill rather than brain injury Aquatic Toxicology 126:116-127.

Canesi, L,C. Ciacci, D. Vallotto, G. Gallo, A. Marcomini \& G. Pojana 2010.

In vitro effects of suspensions of selected nanoparticles (C60 fullerene, $\mathrm{TiO}_{2}, \mathrm{SiO}_{2}$ ) on Mytilus hemocytes. Aquatic Toxicology 96: 151-158.

Evelyn, T.P.T. 2002.

Finfish immunology and its use in preventing infectious diseases in cultured fin fish. In: Lavilla-Pitogo C.R. and E.R. Cruz-Lacierda (eds) Diseases in Asian Aquaculture IV, Fish Health Section, Asian Fisheries Society, Manila, Philippines pp. 303-324.

Federici, G, B.J. Shaw \& R.D. Handy 2007.

Toxicity of titanium dioxide nanoparticles to rainbow trout (Oncorhynchus mykiss): Gill injury, oxidative stress, and other physiological effects. Aquatic Toxicology 84: 415-430.

Griffitt, R.J., J. Luo, J. Gao, J.C. Bonzongo \& D.S. Barber 2008.

Effects of particle composition and species on toxicity of metallic nanomaterials in aquatic organisms. Environmental Toxicology and Chemistry 27: 1972-1978.

Gurr, J. R, A.S.S. Wang, C.H. Chen, \& K.Y. Jan 2005.

Ultrafine titanium dioxide particles in the absence of photoactivation can induce oxidative damage to human bronchial epithelial cells. Toxicology 213: 66-73.

Handy, R.D, N. van den Brink, M. Chappell, M. Mühling, R. Behra, M. Dus inska, P. Simpson, J. Ahtiainen, A.N. Jha, J. Seiter, A. Bednar, A. Kennedy, T.F. Fernandes \& M. Riediker 2012.

Practical considerations for conducting ecotoxicity test methods with manufactured nanomaterials: What have we learnt so far? Ecotoxicology 21: 933-972.

Hao, L., Z. Wang, \& B. Xing 2009.

Effect of sub-acute exposure to $\mathrm{TiO}_{2}$ nanoparticles on oxidative stress and histopathological changes in Juvenile Carp (Cyprinus carpio). Journal of Environmental Science 21: 1459-1466. 
Hall, S., T. Bradley, J.T. Moore, T. Kuykindall, \& L. Minella 2009.

Acute and chronic toxicity of nano-scale $\mathrm{TiO}_{2}$ particles to freshwater fish, cladocerans, and green algae, and effects of organic and inorganic substrate on $\mathrm{TiO}_{2}$ toxicity. Nanotoxicology 3: 91-97.

Hesser, E.F. 1960.

Methods for routing fish haematology. Progressive Fish Culturist 22: 164-171.

Hibiya, T. 1982

An atlas of Fish Histology-Normal and Pathological features. Kodansha, Tokyo, Japan 147 p.

Jovanovic' B, L. Anastasova, E.W. Rowe, Y. Zhangc, A. R. Clapp \& D. Palic 2011.

Effects of nanosized titanium dioxide on innate immune system of fathead minnow (Pimephales promelas Rafinesque, 1820). Ecotoxicology and Environmental Safety 74: 675-683.

Jovanovi'c B. \& D. Pali'c 2012.

Immunotoxicology of non-functionalized engineered nanoparticles in aquatic organisms with special emphasis on fish-Review of current knowledge, gap identification, and call for further research. Aquatic Toxicology 118-119: 141-151.

Kahru, A. \& H.C. Dubourguier 2010.

Review: From ecotoxicology to nanoecotoxicology. Toxicology 269: 105-119.

Menard, A., D. Drobne \& A. Jemec 2011.

Ecotoxicity of nanosized $\mathrm{TiO}_{2}$. Review of in vivo data. Environmental Pollution 159: 677-684.

Murray, C.K., \& T.C. Fletcher 1976.

The immunohistochemical localization of lysozyme in plaice (Pleuronectes platessa L.) tissues. Journal of Fish Biology 9: 329-334.

Pathiratne, A., L.W.H.U. Chandrasekera \& K.A.S. Pathiratne 2009.

Use of biomarkers in Nile tilapia (Oreochromis niloticus) to assess the impacts of pollution in Bolgoda Lake, an urban water body in Sri Lanka. Environmental Monitoring and Assessment 156: 361-375.

Ramsden, C.S, T.J. Smith, B.J. Shaw \& R.D. Handy 2009.

Dietary exposure to titanium dioxide nanoparticles in rainbow trout (Oncorhynchus mykiss): no effect on growth, but subtle biochemical disturbances in the brain. Ecotoxicology18: 939-951.

Ramsden, C.S., T.B. Henry, \& R.D. Handy 2013.

Sub-lethal effects of titanium dioxide nanoparticles on the physiology and reproduction of zebrafish. Aquatic Toxicology 126: 404-413.

Reeves, J.F., S.J. Davies, N.J.F. Dodd \& A.N. Jha 2008.

Hydroxyl radicals $(\mathrm{OH})$ are associated with titanium dioxide $\left(\mathrm{TiO}_{2}\right)$ nanoparticle-induced cytotoxicity and oxidative DNA damage in fish cells. Mutation Research 640: 113-122. 
Scown, T.M., R. Van Aerle \& C.R. Tyler 2010.

Review: Do engineered nanoparticles pose a significant threat to the aquatic environment. Critical Review of Toxicology 40(7): 653-670.

Wang, J., G. Zhou, C. Chen, H. Yu, T. Wang, Y. Ma, G. Jia, Y. Gao, B. Li, J. Sun, Y. Li, F. Jiao, Y. Zhao \& Z. Chai 2007.

Acute toxicity and biodistribution of different sized titanium dioxide particles in mice after oral administration. Toxicology Letters 168: 176185.

Wang, J., X. Zhu, X. Zhang, Z. Zhao, H. Liu, R. George, J. Wilson-Rawls, Y. Chang, \& Y. Chen 2011.

Disruption of zebrafish (Danio rerio) reproduction upon chronic exposure to $\mathrm{TiO}_{2}$ nanoparticles. Chemosphere 83: 461-467.

Whyte, S.K. 2007.

The innate immune response of finfish-A review of current knowledge. Fish and Shellfish Immunology 23: 1127-1151.

Zar, J.H. 1999.

Biostatistical Analysis, Prentice Hall, Upper Saddle River, New Jersey, $663 \mathrm{p}$. 